\title{
ELABORAÇÃO E APLICAÇÃO DE UM RECURSO LÚDICO-DIDÁTICO VISANDO À SENSIBILIZAÇÃO AMBIENTAL RELACIONADA À TEMÁTICA ÁGUA
}

\author{
DEVELOPMENT AND APPLICATION OF A PLAYFUL-DIDACTIC RESOURCE \\ AIMED AT ENVIRONMENTAL AWARENESS RELATED TO THE WATER THEME
}

\author{
Maria das Graças Cleophas ${ }^{1}$ \\ Raquel Rodrigues Dias ${ }^{2}$
}

\begin{abstract}
Resumo: Este artigo traz os resultados levantados de uma pesquisa realizada no âmbito da execução de um projeto de extensão cuja meta consistiu na aplicação de uma proposta lúdicodidática envolvendo a elaboração de um álbum de figurinhas Aquas que visava favorecer o letramento científico e estimular a tomada de decisão frente às questões ambientais. A natureza da pesquisa é qualitativa e consiste de uma investigação-ação realizada com alunos da educação básica de uma escola pública, professores e pesquisadores. Os resultados empíricos do processo de desenvolvimento e aplicação do álbum de figurinhas apontam que a proposta lúdico-didática contribuiu para motivar os alunos para a aprendizagem de temas científicos, fomentou o incentivo à pesquisa e a sensibilização ambiental sobre os problemas atrelados à temática água, entre outros benefícios.
\end{abstract}

Palavras-chave: Atividade lúdica. Educação Ambiental. Ensino de Ciências.

Abstract: This article brings the results of a research carried out in the scope of the execution of an extension project whose goal consisted in the application of a ludic-didactic proposal involving the elaboration of an album of cards Aquas that aimed to favor the scientific literacy and to stimulate the decision-making regarding environmental issues. The nature of the research is qualitative and consists of an action-research carried out with students of the basic education of a public school, teachers and researchers. The empirical results of the process of developing and applying the album of figurines point out that the ludic-didactic proposal contributed to motivate the students to learn scientific subjects, fomented the incentive to research and the environmental awareness about the problems linked to the water theme, among other benefits.

Keywords: Playful activities. Environmental education. Science Teaching.

\footnotetext{
${ }^{1}$ Doutora em Ensino das Ciências, pela Universidade Federal Rural de Pernambuco. Professora Adjunta de Química, da Universidade Federal da Integração Latino-Americana (UNILA); Professora do Programa de Pósgraduação em Educação em Ciências e em Matemática, da Universidade Federal do Paraná no Programa de Pósgraduação Interdisciplinar em Energia e Sustentabilidade, da UNILA, Foz do Iguaçu, Paraná, Brasil. E-mail: maria.porto@unila.edu.br

${ }^{2}$ Mestranda no Mestrado Profissional em Química em Rede Nacional, da Universidade Tecnológica Federal do Paraná, Paraná, Brasil; licenciada em Ciências da Natureza e em Química, ambos pela UNILA. Professora de Química e Física na educação básica. E-mail: rdrodrigues23@gmail.com
} 


\section{Introdução}

Recentemente, temos encontrado na literatura vários trabalhos relatando o uso do lúdico em diferentes ambientes e níveis de ensino. Contudo, muitas vezes, a didatização lúdica (CLEOPHAS; SOARES, 2018) dos processos educativos permanece quase que restritamente atrelada à representatividade do jogo, seja ele didático, pedagógico ou educativo. Com isso, é comum não enxergamos o universo que o campo do lúdico pode agregar à educação em ciências, nem tampouco, a pluralidade das formas lúdicas que podem ser ancoradas aos processos de ensino e aprendizagem. Pois, usar uma lente lúdica para ensinar ciências significa promover efeitos positivos na aprendizagem de conceitos científicos por meio do incentivo à diversão.

Dohme (2003) aponta a existência de características que são atribuídas às atividades lúdicas, tais como, a participação ativa do aluno em sua aprendizagem, aumento da participação, o exercício de aprender fazendo, o desenvolvimento de habilidades, entre outras. Nessa direção, Herrera e Barbosa (2014) afirmam que ao brincar são estabelecidos relacionamentos com objetos, situações e pessoas e, assim, o desenvolvimento cognitivo é aprimorado, especialmente para resolver problemas e criar novos conhecimentos.

$\mathrm{Na}$ escola de hoje, se faz necessário diversificar as estratégias didáticas de modo a possibilitar diferentes maneiras de resolver um dado problema. Para Rodrigues (2012), as escolas enfrentam efetivas dificuldades para concretizar a missão e os objetivos que lhe são atribuídos no sentido de garantir que todos os alunos aprendam e atinjam níveis de qualidade em suas aprendizagens. Como estratégia para sanar tais problemas, a construção de materiais didáticos lúdicos pode ser tornar uma parceira do professor e do aluno, pois, conforme salientam Fernández-Oliveras, Correa e Oliveras (2016), o que é ensinado e aprendido de uma forma lúdica, persiste com a passagem do tempo.

Com efeito, o ensino de ciências praticado nas escolas ainda faz uma fraca articulação com a Educação Ambiental (EA). Isto denota, muitas vezes, um falso discurso, já que a EA consiste de um tema amplo e deveria estar inserido em todo o currículo da educação básica e do ensino superior, entretanto, como ela pertence a todas as disciplinas do currículo, acaba sofrendo um certo tipo de 'omissão' por parte dos professores, pois não é agregada de forma adequada no ensino de ciências ou ainda, é deixada de lado por acreditar que algum outro docente já se incumbiu de discuti-la em suas aulas. Nesse viés, como forma de amenizar o

\footnotetext{
\begin{tabular}{l|ll}
\multirow{2}{*}{ REVISTA } & EXTENSÃO \& CIDADANIA \\
\cline { 2 - 3 } & v. 8, n. 14, p. 74-92, jul./dez. 2020. ISSN 2319-0566
\end{tabular}
} 
distanciamento da EA com o ensino de ciências, "o campo de construção de materiais instrucionais visando à promoção de uma educação ambiental significativa se torna uma seara de elevado potencial" (FREIRE PINTO; CLEOPHAS, 2016, p. 3 ).

Este artigo vai ao encontro do que defende Ballesteros (2011), ou seja, que a competência científica não é apenas a aprendizagem de conhecimentos e procedimentos, mas também a construção de uma atitude e um modo de compreender o mundo e de agir responsavelmente com base na interação social através do diálogo e da cooperação. Nesse seguimento, discutiremos a construção de um recurso lúdico-didático inovador (álbum de figurinhas Aquas) que teve como objetivo entrelaçar a Educação Ambiental ao ensino de ciências, numa perspectiva vinculadora entre a pesquisa na área de educação em ciências e a extensão universitária.

Em suma, este artigo apresenta resultados de uma pesquisa que envolveu a construção e aplicação do álbum de figurinhas Aquas, realizada no âmbito de uma ação extensionista, desenvolvida com alunos do $1^{\circ}$ ano do Ensino Médio de uma escola pública localizada do Sul do país. A questão de investigação que norteia esta pesquisa é: o álbum de figurinhas Aquas contribuiu com a motivação para assimilação de temas científicos e com a sensibilização da temática ambiental relacionada à água?

\section{Atividades lúdicas no ensino de Ciências para fomentar sensibilização sobre a temática ambiental água}

Em 2015, a Organização das Nações Unidas (ONU) lançou a agenda 2030 que visa ao desenvolvimento sustentável no mundo. Dentre os pontos que compõem a agenda, há um conjunto de 17 Objetivos para o Desenvolvimento Sustentável (ODS) que devem ser cumpridos por todas as populações do planeta terra até o ano de 2030. Este artigo, em especial, levou em consideração dois objetivos da ODS para compor a criação do álbum de figurinhas, ou seja, o Objetivo 6, que assegura a disponibilidade e gestão sustentável da água e saneamento para todo se o objetivo 14, relacionado à conservação e ao uso sustentável dos oceanos, dos mares e dos recursos marinhos para o desenvolvimento sustentável, além de aspectos relacionados aos conhecimentos científicos, questões de cunho histórico, atualidades, sensibilização sobre o uso racional, contextualização, Pegada Hídrica $(\mathrm{PH})$, entre outros aspectos não menos importantes ligados à temática água.

\footnotetext{
\begin{tabular}{l|l}
\multirow{2}{*}{ REVISTA } & EXTENSÃO \& CIDADANIA \\
\cline { 2 - 3 } & v. 8, n. 14, p. 74-92, jul./dez. 2020. ISSN 2319-0566
\end{tabular}
} 
A ideia central era promover a construção de um recurso lúdico-didático inovador que pudesse aproximar, nas aulas de Química, elementos da EA na vida dos alunos, extrapolando assim, os seus benefícios para além da sala de aula. De acordo com Galera e Reyes (2015), o ensino de ciências deve ser abordado com estratégias variadas, visando assim, aproximá-lo de mais crianças com intuito de obter um aprendizado mais profundo. Logo, nas palavras de Nafiati (2015), os professores precisam melhorar suas competências e capacidades para criar um processo de aprendizagem mais humanista e mais adequado aos objetivos da educação.

Defende-se, piamente, que uma educação mais humanista deve abordar a EA nas aulas de Ciências, contribuindo, desse modo, com a investigação e reflexão sobre a ação e reação do sujeito ecológico frente ao consumo sustentável no século XXI (AILIM, 2016), pois, no que tange à problemática da água, a educação é o mecanismo principal pelo qual se promove a sensibilização sobre a importância da água, "como uma mola propulsora da mobilização e participação com vistas ao controle social sobre os recursos" (PICCOLI et al., 2016, p. 799).

Ademais, acredita-se que o desenvolvimento curricular deve ser organizado não apenas em torno de disciplinas, mas em torno de desafios e contextos complexos da vida real, a citar, como exemplo, a problemática mundial que envolve a água. A fim de responder a esses desafios, as atividades lúdicas se tornam um excelente mecanismo para harmonizar a relação entre os problemas ambientais e a educação em ciências necessárias para a construção de uma sujeito crítico-reflexivo de forma vindoura, porque, o lúdico pode construir uma bagagem cultural na criança e se incorporar de modo dinâmico a sua cultura e na capacidade de criação do futuro adulto (WINNICOTT, 1975).

Assim, numa perspectiva holística de formação do sujeito, "o conhecimento gerado a partir da atividade lúdica pode ser transportado para o campo da realidade, caracterizando a transcendência" (COSCRATO; PINA; MELLO, 2010, p. 258), prontamente, o desenvolvimento e aplicação de recursos lúdico-didáticos desempenham um papel fundamental perante o aprimoramento de operações mentais de cunho receptivo (observar, identificar, escutar, etc.), abrangente (comparar, relacionar, resolver problemas, compreender, etc. ) e expressivo simbólico (representar e comunicar) (ALONSO, 2000). Cabe salientar que as operações supracitadas são imprescindíveis às mudanças na forma de conceber o mundo (FERNÁNDEZ-ARROYO; RODRÍGUEZ-MARÍN, 2017).

Adicionalmente, "a educação ambiental do século 21 necessita de um docente inovador que trabalhe com conceitos e temas complexos, pautados na ação crítica local, sob perspectiva

\footnotetext{
\begin{tabular}{l|l}
\multirow{2}{*}{ REVISTA } & EXTENSÃO \& CIDADANIA \\
\cline { 2 - 3 } & v. 8, n. 14, p. 74-92, jul./dez. 2020. ISSN 2319-0566
\end{tabular}
} 
global” (QUERIOZ et al., 2016, p. 17), porque, com a utilização das atividades lúdicas em sala de aula, os professores e alunos têm a possibilidade de construir uma ponte e enveredar por outros caminhos que levem à aprendizagem, driblando o tradicionalismo, ainda contemporaneamente operante, encontrado no ensino (SILVA; LACERDA; CLEOPHAS, 2017) de Ciências em geral.

Ainda sobre o ensino tradicional, há uma consciência de que ele é baseado apenas na memória e na abstração descontextualizada não preparando adequadamente as habilidades necessárias para o século XXI como, por exemplo, o trabalho em equipe, a resolução de problemas e o pensamento crítico (VÁZQUEZ-ALONSO; MANASSERO-MAS, 2016). Em complemento, Castoldi e Polinarski (2009) fazem uma crítica em relação ao professor sobre a utilização exaustiva dos métodos tradicionais de ensino, pois alegam que os professores, muitas vezes, têm medo de inovar ou não se opõem ao tradicionalismo metódico devido à inércia.

Por outro lado, este artigo fortalece a ideia da repaginação metodológica por meio da criatividade, elaboração e inserção de um recurso lúdico-didático inovador como um álbum de figurinhas, visando, dessa maneira, contribuir com o empoderamento social e ambiental sobre a sensibilização quanto ao uso da água. Barnett (2007) aponta a necessidade de entrelaçar conhecimento (epistemologia), ação (práxis) com o ser (ontologia). Seguindo a mesma linha de raciocínio, o álbum vai ao encontro da sinergia proposta pelo autor, dado que favorece a aquisição de conhecimentos científicos, permite a prática por meio da transposição das informações adquiridas e promove uma reflexão do sujeito frente a sua própria realidade no condizente a sua postura em relação aos problemas atrelados à temática água.

\section{Desenho da investigação}

A pesquisa consiste de uma investigação-ação (TRIPP, 2005), foi desenvolvida ao longo da execução de uma ação extensionista intitulada "Construção de recursos didáticos para o empoderamento da temática Água: jogos didáticos e sua importância para o ensino e aprendizagem de temas transversais". Cabe frisar que durante todo o processo de execução da proposta houve produção do saber, através da reflexão sobre cada uma das etapas que compuseram a ação, proporcionando, certamente, um aumento de conhecimento de todas as pessoas envolvidas na situação e no contexto investigado (AMADO, 2017). A pesquisa visou, sobretudo, contribuir com uma prática educativa transformadora que pudesse refletir na

\footnotetext{
\begin{tabular}{l|l}
\multirow{2}{*}{ REVISTA } & EXTENSÃO \& CIDADANIA \\
\cline { 2 - 3 } & v. 8, n. 14, p. 74-92, jul./dez. 2020. ISSN 2319-0566
\end{tabular}
} 
mudança de atitudes dos sujeitos, tornando-os mais conscientes em relação ao meio ambiente, em especial, aos enfrentamentos necessários relacionados à água.

A pesquisa envolveu 17 alunos da educação básica, ensino regular, matriculados no $3^{\circ}$ ano do Ensino Médio de uma escola pública pertencente à região Sul do país. Deste total, 9 pertenciam ao gênero feminino, 7 ao gênero masculino e 1 preferiu não informar. Para a coleta de dados, optou-se pela aplicação de questionário semiestruturado aos 17 participantes, além dos registros coletados em um diário de bordo pelos discentes de um curso de licenciatura que faziam parte da equipe. Os dados levantados durante a investigação-ação foram agrupados por similitudes e, também, por tipo de questão (aberta ou fechada).

\section{Descrição do álbum, objetivos, estrutura e especificações}

O Aquas é um álbum de figurinhas temático e de cunho pedagógico, totalmente ilustrado, traz uma abordagem transversal sobre a água. O álbum vai ao encontro dos objetivos preconizados pela Educação Básica que, entre tantos outros, visa promover a educação científica de alunos, ajudando-os a construir diferentes conhecimentos que dialoguem com a sua realidade socioambiental. Assim, o álbum foi estrategicamente elaborado para favorecer a construção de um pensamento crítico e reflexivo sobre um tema que apresenta relevância global e que, muitas vezes, no contexto educacional, não é explorado de forma correta, pois não beneficia a construção de conhecimentos transversais que favoreçam uma formação de valores e princípios, permitindo, desse modo, que os alunos possam estabelecer uma ampla relação entre cidadania, sustentabilidade e responsabilidade social.

Pode-se mencionar que o campo para a proposição e/ou adaptação de estratégias didático-metodológicas é amplo. Deste modo, o álbum de figurinhas surge como uma estratégia lúdico-didática viável para o ambiente educacional. Consistindo em uma proposta que possui em seu escopo um elevado caráter inovador, pois visa ampliar o leque de estratégias pedagógicas que podem ser utilizadas no ensino das Ciências da Natureza. O álbum pode ser utilizado em todos os níveis educacionais e demonstra alto potencial para estabelecer conexões entre diferentes campos de conhecimentos, o que denota o seu caráter interdisciplinar. É dinâmico, empolgante, divertido, mas sem perder sua essência maior, ou seja, a promoção do letramento científico para a formação dos alunos, além de estimular a tomada de decisão frente às questões ambientais. 
O Aquas não é um simples álbum de figurinhas, não é "mecânico", pois faz com que o aluno pense e estabeleça relações entre diferentes áreas do conhecimento. Defende-se que a proposta aqui apresentada se configura em um recurso lúdico-didático com elevado potencial inovador para o ensino de ciências devido à sua capacidade de auxiliar alunos no desenvolvimento de habilidades cognitivas ao estimular o raciocínio, o prazer, a motivação, além de potencializar aspectos relacionados com a interação social entre os sujeitos que fazem uso do álbum. Resumidamente, o Quadro 1, exibe os objetivos, conteúdos científicos e temas abordados em relação à agua que estão presentes no Aquas.

Quadro 1 - Objetivos, conteúdos científicos e temas abordados no álbum de figurinhas

\begin{tabular}{|c|c|}
\hline \multirow{7}{*}{ Objetivos } & Incentivar a criatividade \\
\hline & Desenvolver o pensamento crítico \\
\hline & Estimular a cooperação \\
\hline & Resolver problemas \\
\hline & Ampliar habilidades cognitivas \\
\hline & Promover sensibilização ambiental \\
\hline & Instigar a inteligência social \\
\hline \multirow{5}{*}{$\begin{array}{l}\text { Conteúdos } \\
\text { científicos }\end{array}$} & Forças intermoleculares \\
\hline & Solubilidade \\
\hline & Reações químicas \\
\hline & Anomalias termodinâmicas da água \\
\hline & Estados físicos da matéria \\
\hline \multirow{10}{*}{$\begin{array}{l}\text { Temas abordados } \\
\text { em relação à agua }\end{array}$} & Doenças \\
\hline & Curiosidades \\
\hline & Contextualização das Cataratas do Iguaçu em relação ao cotidiano dos alunos \\
\hline & Usos da água no mundo (estatísticas) \\
\hline & Energia e impactos ambientais \\
\hline & Aquíferos \\
\hline & Legislação ambiental \\
\hline & Desastres ambientais (em especial, o Desastre de Mariana) \\
\hline & Pegada Hídrica (PH) \\
\hline & Aspectos históricos \\
\hline
\end{tabular}

Fonte: Elaboração da autora.

$\mathrm{O}$ álbum de figurinhas Aquas é composto por sete seções, sendo, Água em foco; $\mathrm{H}_{2} \mathrm{O}$ Science; Cataratas do Iguaçu; Água no planeta; Pegada Hídrica; Curiosidades e Use com moderação. O Aquas foi confeccionado em papel couchê fosco 300 gramas, contendo 12 páginas no formato A4 com impressão laser colorida. O álbum é composto por 80 figurinhas que foram agrupadas, aleatoriamente, em 20 pacotinhos personalizados. Com efeito, o Aquas não consiste de um álbum de figurinhas comum. 
Ao contrário dos álbuns convencionais que possuem uma estrutura de apenas 'acha e cola', no Aquas, as figurinhas respondem uma pergunta que está exibida no álbum e, em outras, elas complementam a informação inserida, ou ainda, são perguntas, já que as respostas podem estar descritas no campo da figurinha correspondente. Devido à quebra de previsibilidade, o álbum é cognitivamente provocativo, tende a favorecer a curiosidade, a apropriação e mobilização de saberes já previamente adquiridos e também promove a pesquisa, entre outros benefícios que são importantes no processo de aprendizagem. A Figura 1 mostra o desenho gráfico do álbum, partes do álbum impresso, figurinhas e 'pacotinhos'.

Figura 1 - O álbum de Figurinhas Aquas
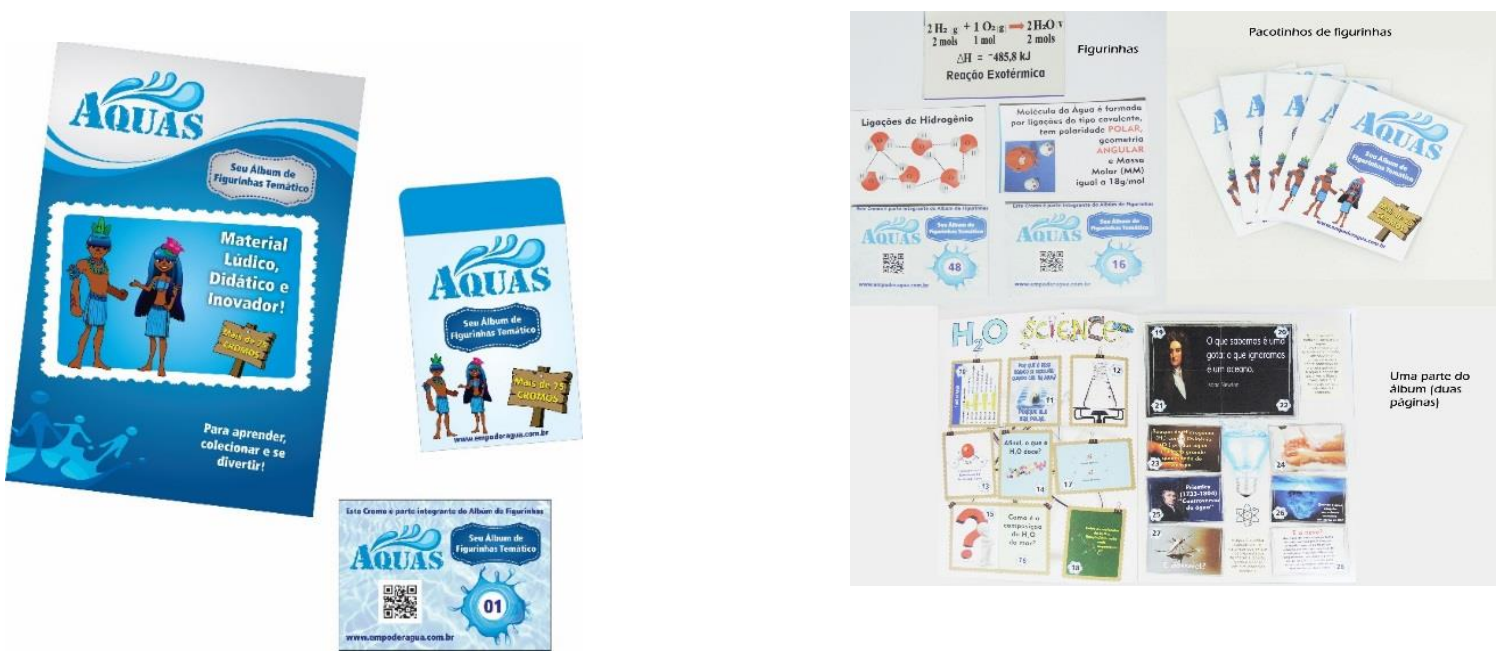

Fonte: Acervo pessoal.

\section{Sequência didática}

Inicialmente, a professora da turma levantou várias questões sobre a temática água, promovendo assim, pequenos debates entre os alunos da turma. Na ocasião, o rompimento da barragem de Fundão, ocorrido no município de Mariana (MG), estava no auge midiático, pois, o desastre repercutiu no mundo inteiro por ser considerado o maior acidente ambiental causado por despejo de rejeitos de mineração. Assim, o Desastre de Mariana foi utilizado como tema 
gerador, visando uma ação "educativa ambiental crítica, transformadora e emancipatória" (TOZONI-REIS, 2006, p. 93).

Após as discussões, a professora fez a entrega de um álbum e três pacotes de figurinhas para cada aluno. A proposta lúdico-didática teve duração de uma semana, assim, os alunos, ao executarem as atividades extraclasse em formato de missões, eram recompensados com pacotinhos adicionais de figurinhas e recebiam o feedback da professora sobre o seu desempenho na execução das tarefas. Nesse ínterim, os alunos, naturalmente, explicitaram a necessidade de promover o diálogo com os seus colegas sobre os conteúdos inseridos no álbum, bem como, efetuar a trocar das figurinhas repetidas, gerando assim, interação social, motivação, cooperação, reflexão, etc. Com efeito, houve um esforço, por parte da professora, para promover uma dinâmica colaborativa em vez de competitiva (SÁNCHEZ-MARTíN; CAÑADA-CAÑADA; DÁVILA-ACEDO, 2017) entre a turma. Deve-se enfatizar que este estudo, por mais que não tenha como foco principal discutir a gamificação, é notório a sua presença na sequência didática construída. Isto significa que a proposta lúdico-didática aqui apresentada permitiu que os alunos recebessem recompensas (figurinhas) para 'subir de nível' através do currículo, concluindo assim, as missões (KINGSLEY; GRABNER-HAGEN, 2015) solicitadas pela professora.

De um modo geral, a sequência didática abarcou as dimensões da abordagem 'Pesquisa Responsável e Inovação’ (Responsible Research and Innovation - RRI) como estratégia para fortalecer a compreensão holística dos sujeitos sobre a relação entre a ciência, o lúdico e a EA, perante a formação de cidadãos crítico-reflexivos sobre a temática água. Assim, dentro desse contexto, a RRI, na educação científica pode ser vivenciada de forma significativa, pois enfatiza a importância da participação ativa, bem como a responsabilidade dos alunos pela descoberta do conhecimento (BARDONE et al., 2017). Logo, inserir as dimensões da RRI nos currículos da educação básica é equipar os alunos para cuidar do futuro por meio da administração responsável de práticas de pesquisa e inovação que abordem os grandes desafios do nosso tempo de forma colaborativa, ética e, sobretudo, sustentável (TASSONE et al., 2017). A Figura 2 exemplifica cada dimensão da RRI e sua imediata adaptação para a proposta desenvolvida. 
Figura 2 - Dimensões da RRI inseridas na proposta lúdico-didática

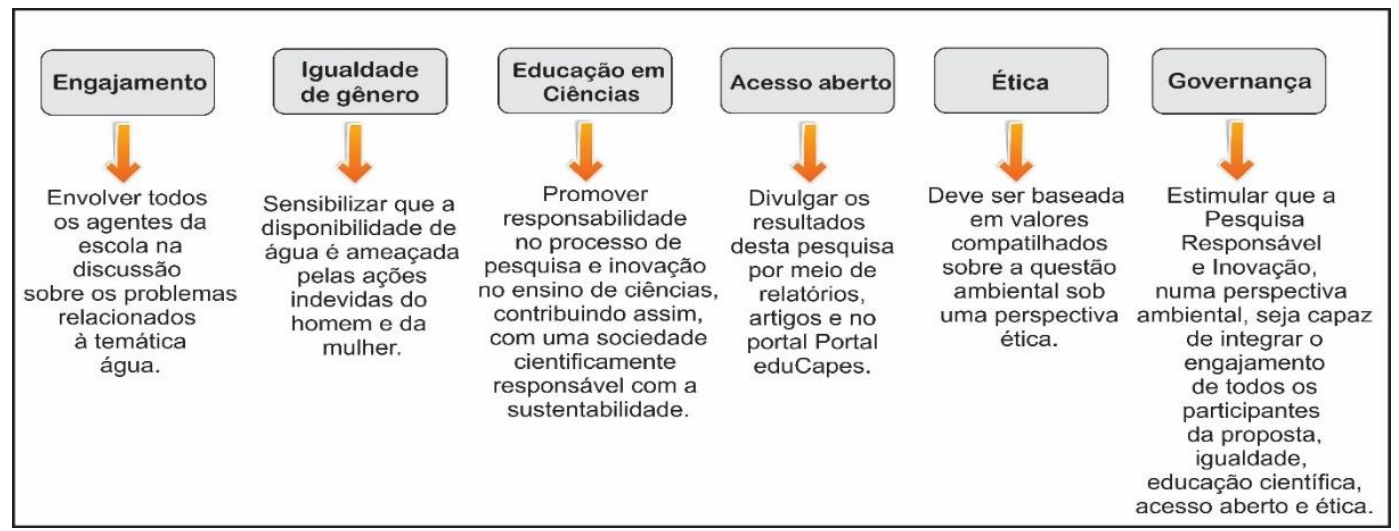

Fonte: Adaptado de Apotheker et al. (2017).

Ao final da atividade, com o intuito de obter informações concretas sobre a receptividade da proposta lúdico-didática pelos alunos, foi solicitado que eles respondessem, de modo anônimo, o questionário exposto na Tabela 1. O questionário foi elaborado utilizando o google formulários, desse modo, foi entregue a cada aluno um link que dava acesso às questões.

Tabela 1 - Questões aplicadas aos alunos visando à avaliação da proposta lúdico-didática

1. Descreva sua experiência em utilizar o álbum de figurinhas.

2. Como você classifica o uso do álbum de figurinhas como auxílio para sua aprendizagem?

3. Gostaria que outros professores utilizassem o álbum de figurinhas em suas disciplinas?

4. Você se sentiu estimulado a pesquisar/aprofundar mais sobre algum assunto/tema do álbum?

5. Você se sentiu motivado em realizar as tarefas (extraclasse) que a professora solicitou como complemento da atividade realizada com o uso do álbum? Justifique.

6. Aponte falhas em relação ao uso do álbum ou qualquer outra situação que tenha atrapalhado você.

Fonte: Dados da Pesquisa. 


\section{Resultados}

A partir de agora, serão discutidos os resultados que permitirão avaliar a proposta lúdico-didática e apontar os possíveis benefícios do álbum de figurinhas para a sensibilização sobre a temática água. É importante destacar que a proposta executada teve um caráter multi e interdisciplinar envolvendo a temática água. Os alunos, quando questionados acerca da sua experiência em utilizar o álbum de figurinhas Aquas, emitiram opiniões bem expressivas, tais como:

(a) Muito boa, achei a ideia didática excelente e divertida.

(b) Eu diria que muito boa.... No álbum descobri várias coisas que eu não sabia antes.

(c) Achei/estou achando uma ótima ideia. Tanto dinâmica quanto conscientizadora... é uma boa forma de se aprender coisas.

(d) É legal por ser um "método" novo de ensino, bem mais legal e mais divertido de estudar...

Percebe-se que a proposta lúdico-didática contribuiu com o aumento da motivação para a aprendizagem. Sob este aspecto, é amplamente salutar que professores diversifiquem suas estratégias de ensino, promovendo, assim, desafios adequados que possam envolver os alunos em compromissos de investir em sua própria aprendizagem. Nessa perspectiva, quando a atividade lúdica é planejada corretamente, ela pode representar um elemento-chave no processo de ensino, favorecendo uma aprendizagem qualitativamente dos alunos (OJA-PERSICHETO, 2017). Neste trabalho, buscou-se construir uma proposta didático-lúdica que dialogasse com uma visão crítica de Educação Ambiental, ou seja, “com uma visão sistêmica de meio ambiente, compreendido em sua totalidade complexa como um conjunto no qual seus elementos/partes interdependentes interrelacionam entre si” (GUIMARÃES, 2017, p. 17).

Os alunos foram questionados em relação aos dois itens (questões fechadas) do questionário semiestruturado. Os dados coletados foram representados no Gráfico 1, a questão 2 solicitava que cada aluno classificasse o uso do álbum de figurinhas como auxílio para sua aprendizagem. Os resultados mostram que $88,2 \%(n=15)$ alunos consideraram a proposta lúdico-didática ótima. Todavia, deve-se considerar que este resultado exibe que a proposta, de fato, foi motivadora para o aluno frente à temática abordada. Porém, deve-se "compreender que a utilidade do "gostar" está no motivar o discente para o estudo" (GARCEZ; SOARES, 2017, p. 205), consistindo, portanto, de uma possibilidade ímpar de instigar a aprendizagem de conceitos mais complexos, com vistas a diminuir as dificuldades de abstração dos alunos sobre temas conexos à ciência. A questão 3 também traz à tona a elevada aceitação da proposta pelos 
alunos. O álbum corrobora com as ideias de C-Abt (1974, p. 24), que demonstra apresentar potencial para ser utilizado nas escolas para "identificar tipos de aptidões não verbais, tais como, solução cognitiva de problemas, negociação social e habilidades de comunicação".

Gráfico 1 - Referente às questões 2 e 3 apresentadas na Tabela 1

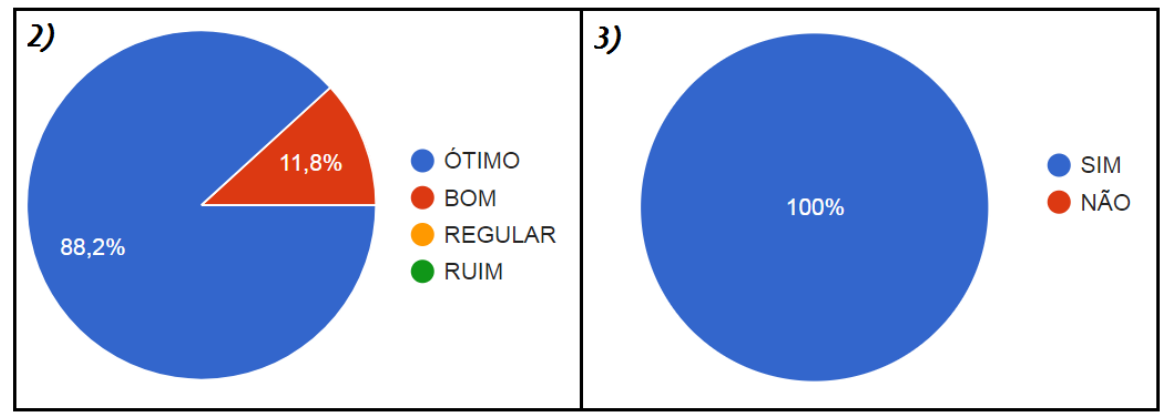

Fonte: Dados da Pesquisa.

No que diz respeito ao item que se refere ao estímulo à pesquisa, o álbum mostrou-se ser eficaz, conforme pode ser observado nos recortes textuais a seguir:

(d) Sim, por envolver interação com os colegas.

(e) Sim, porque tinha um monte de coisa legais e você aprendia colando as figurinhas.

(f) Sim, pois cada vez mais a curiosidade, para saber mais informações, vai aumentando.

(g) Sim, pois ali não tem tudo o que se precisa saber sobre a água. Pesquisei na internet algumas coisas.

(h) Sim, fui pesquisar mais como economizar cada vez mais a água.

Observa-se, nos recortes dados, que o álbum incentivou a pesquisa, contribuindo com a construção de um papel mais ativo do aluno em relação a sua aprendizagem. Nessa direção, Michael (2006) reforça a ideia da necessidade dos estudantes realizarem tarefas que necessitem de reflexão de ideias e, sobretudo, capacidade de saber usá-las quando requeridas. Igualmente, o álbum favoreceu a interação entre os colegas (D), a curiosidade (F), e dar indícios de mudança de postura nas ações do sujeito $(\mathrm{H})$. Nesse viés, o álbum também evidencia possibilidades para a EA, pois pode "proporcionar o desenvolvimento de um posicionamento crítico, tornado os sujeitos envolvidos em cidadãos capazes de rediscutir valores existentes em sua realidade" (DIAS; BOMFIM, 2011, p. 6).

Além da boa receptividade apontada pelos alunos sobre a proposta lúdico-didática, é 
importante destacar que eles também demonstraram elevada dedicação ao cumprimento das tarefas solicitadas pela professora. É importante mencionar que a professora sempre atribuía um feedback sobre as atividades requeridas, dando chance assim dos alunos acompanharem o desenvolvimento de seu desempenho (ARCHER; CRISPIM; CRUZ, 2016) durante a realização da proposta. Cada aluno foi questionado sobre sua motivação em realizar as tarefas (extraclasse) que a professora solicitava em complemento da atividade realizada com o uso do álbum. Algumas opiniões podem ser observadas abaixo:

(i) Sim, porque estimula a gente ter compromisso e agilidade para entregar as tarefas no tempo determinado.

(j) Sim, ficava ansiosa para saber a próxima tarefa.

(k) Sim. Pois além de ter a oportunidade de completar o álbum, tive a oportunidade de ter maior convívio...

(1) Sim, porque além de aprender com mais diversão, tem o fato de completar o álbum...

Das opiniões citadas, nota-se que o álbum demonstrou ser uma valiosa estratégia, podendo "contribuir perante a formação de sujeitos capazes de ler o mundo de forma crítica e consciente, porém, sem perder de vista a motivação e alegria de (re)descobrir o mundo ao seu redor" (SILVA; LACERDA; CLEOPHAS, 2017, p. 133). O aluno K também destaca a questão do convívio e da motivação extrínseca causada pelo álbum (aluno J), algo que deve ser fortemente incentivado em uma proposta lúdico-didática, pois, conforme garantem Niles e Socha (2014), o professor deve conduzir toda a atividade lúdica sem perder o seu caráter livre e, nem tampouco, o seu caráter pedagógico, de modo a assegurar a interação social e o aumento de habilidades intelectivas. As opiniões levantadas também fortalecem os argumentos de Alves (2009), uma vez que a possibilidade de propor o ensino de determinados conteúdos por meio da brincadeira, faz com que o professor também possua controle sobre os rumos da atividade. Neste caso, o álbum atuou como uma estratégia reguladora para a aprendizagem dos alunos. A Figura 3, mostra que a atividade proposta contribuiu com a interação social. 
Figura 3 - Alunos envolvidos com o álbum de figurinhas Aquas

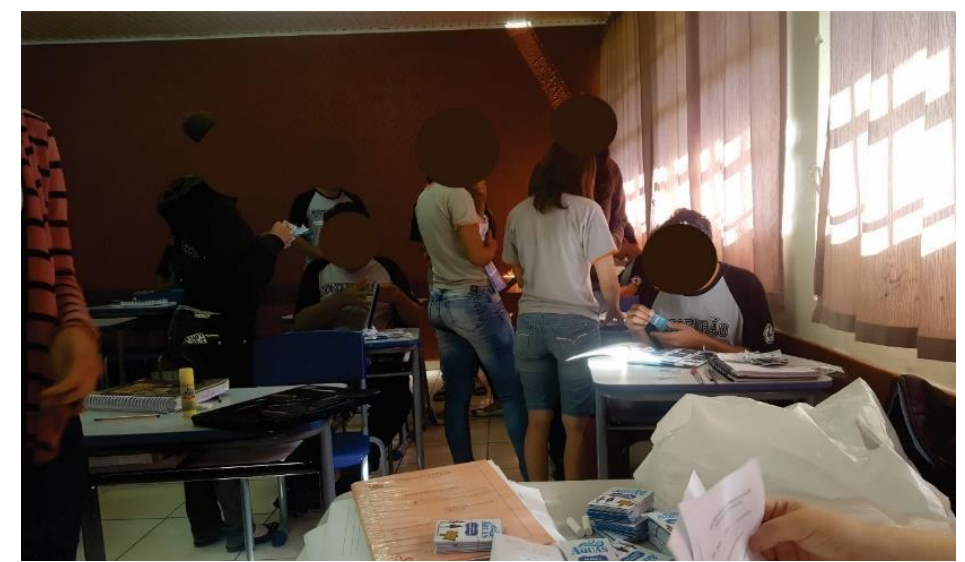

Fonte: Dados da pesquisa.

Finalmente, visando invectivar uma visão crítica-construtivista sobre a proposta lúdicodidática, foi solicitado que os alunos apontassem falhas em relação ao uso do álbum ou qualquer outra situação que os tivessem acarretado dificuldades. Os alunos se posicionaram da seguinte forma:

(m) Alguns quadrados onde era para colar figurinhas tinham informações importantes que tiveram figurinhas com imagens simples coladas em cima, anulando a existência da explicação e consequentemente nos fazendo esquecer o que significava aquela imagem colada.

(n) Recebi figurinhas repetidas.... Isso me atrasou um pouco.

(o) As informações não deviam ser cobertas pelas figurinhas.

(p) Não houve comigo nenhum tipo de situação que tenha me atrapalhado.

As colocações atribuídas às figurinhas contribuíram para analisar o álbum na perspectiva do feedback do aluno sobre o álbum produzido, dado assim, condições da equipe elaboradora do álbum aprimorar a proposta didático-lúdica. Os alunos $\mathrm{M}$ e O fizeram uma colocação bastante interessante, pois, de fato, o desenho do álbum foi idealizado para que não fosse um álbum de figurinhas comum, em oposição à previsibilidade, a ideia central do álbum era contribuir com o desenvolvimento cognitivo, afetivo, social e ambiental.

\section{Implicações e sugestões}

O álbum de figurinhas foi elaborado com materiais de alta qualidade, a separação

\begin{tabular}{l|l}
\multirow{2}{*}{ REVISTA } & EXTENSÃO \& CIDADANIA \\
\cline { 2 - 3 } & v. 8, n. 14, p. 74-92, jul./dez. 2020. ISSN 2319-0566
\end{tabular}


aleatória e contagem das figurinhas em pacotes demanda tempo adicional ao professor, devido ao custo elevado de produção do álbum, a sua aplicação em turmas com grande número de alunos se torna complexa. Todavia, fugindo do modelo empregado neste artigo, é possível propor a construção de álbuns de figurinhas pelos próprios alunos, utilizando materiais de baixo custo, tais como cartolina, cola, tesoura, revistas e jornais para produzir as figurinhas. Assim, como em qualquer outra atividade lúdica com fins pedagógicos, o planejamento deve ser fundamental, aliando-se, dessa maneira, à criatividade e à inventividade, pressupostos necessários para a execução de uma proposta lúdica que vise fomentar a responsabilidade dos alunos pela descoberta do conhecimento.

\section{Considerações finais}

Neste artigo, apresentamos uma proposta lúdico-didática, por meio da construção e aplicação de um recurso lúdico-didático inovador (álbum de figurinhas Aquas) para alunos de uma escola pública, matriculados no $3^{\circ}$ ano de Ensino Médio. O objetivo desta atividade foi aumentar a motivação dos alunos para aprendizagem de temas científicos e sensibilização sobre os problemas ambientais relacionados à água. Os resultados empíricos do processo de desenvolvimento e de aplicação do álbum de figurinhas Aquas evidenciaram a importância da repaginação das atividades pedagógicas no ambiente escolar.

A proposta lúdico-didática desenvolvida apresentou elevada receptividade pelos alunos, revelando, assim, que o resultado foi extremamente positivo no que tange à motivação para aprender e maior sensibilização ambiental. Os alunos participaram ativamente dos desafios/missões entregues pela professora, denotando uma participação mais ativa em seu próprio processo de aprendizagem, além de engajamento que refletiu em um melhor desempenho.

Durante a proposta lúdico-didática, os alunos tiveram a oportunidade de testar seus conhecimentos de forma individual e colaborativa, os participantes da investigação-ação, definiram com suas próprias palavras que a proposta foi "divertida, diferente, intrigante, motivadora, cooperativa e, acima de tudo, muito divertida”. Como futura linha de pesquisa, pretende-se continuar elaborando álbuns de figurinhas com outras temáticas científicas e envolvendo a educação ambiental numa perspectiva crítica.

Por fim, o álbum de figurinhas Aquas forneceu indícios que nos leva a acreditar que ele

\footnotetext{
\begin{tabular}{l|l}
\multirow{2}{*}{ REVISTA } & EXTENSÃO \& CIDADANIA \\
\cline { 2 - 3 } & v. 8, n. 14, p. 74-92, jul./dez. 2020. ISSN 2319-0566
\end{tabular}
} 
contribuiu com a motivação para aprender temas científicos diversos, colaborou com o incentivo à pesquisa e na sensibilização da temática ambiental relacionada à água. Esta pesquisa também demonstrou que o campo do lúdico no ambiente educacional pode ser explorado de diversas maneiras, bastando, para tanto, criatividade, planejamento e dedicação dos professores em elaborar propostas que sejam diferentes de jogos.

\section{Agradecimentos}

À Capes/ANA, pelo auxílio financeiro dado para execução do projeto, e à PROEX/UNILA.

\section{Referências}

AILIM, S. O eco sujeito do século XXI e sua (re)ação ao consumo sustentável em diferentes níveis de ensino com alunos de Ivoti-RS. $201 \mathrm{f}$. Tese (Doutorado em Química) Programa de Pós-Graduação em Educação em Ciências: Química da Vida e Saúde, Instituto de Ciências Básicas da Saúde, Universidade Federal do Rio Grande do Sul, Porto Alegre, 2016.

ALONSO, L. ¿Cuál es el nivel o dificultad de la enseñanza que se está exigiendo en la aplicación del nuevo sistema educativo? Revista educar, n. 26, p. 53-74, 2000.

ALVES, F. D. O lúdico e a educação escolarizada da criança. In: OLIVEIRA, M. L. (org.). (Im)pertinências da educação: o trabalho educativo em pesquisa. São Paulo: Ed. da UNESP; São Paulo: Cultura Acadêmica, 2009.

AMADO, J. Manual de investigação qualitativa em educação. 3. ed. Coimbra: Imprensa da Universidade de Coimbra, 2017.

APOTHEKER, J. et al. Responsible Research and Innovation in secondary school science classrooms: experiences from the project Irresistible. Pure and Applied Chemistry, v. 89, n. 2, p. 211-219, 2017.

ARCHER, A. B.; CRISPIM, A. C.; CRUZ, R. M. Avaliação e feedback de desempenho de estudantes na educação a distância. Avances en Psicología Latino-americana, v. 34, n. 3, p. 473-485, 2016.

BALLESTEROS, O. La lúdica como estrategia didáctica para el desarrollo de competencias científicas. Tesis de Maestría, Facultad de Ciencias, Universidad Nacional, Colombia, 2011.

$$
\begin{array}{l|l}
\multirow{2}{*}{\text { REVISTA }} & \text { EXTENSÃO \& CIDADANIA } \\
\cline { 2 - 3 } & \text { v. 8, n. 14, p. 74-92, jul./dez. 2020. ISSN 2319-0566 }
\end{array}
$$


BARDONE, E.et al. Making Sense of Responsible Research and Innovation in Science Education through Inquiry-Based Learning. Examples from the Field. Science Education International, v. 28 n. 4, p. 293-304, 2017.

BARNETT, R. A will to learn: being a student in an age of uncertainty. Berkshire: McGrawHill/Open University Press, 2007.

C-ABT, C. Jogos simulados. Rio de Janeiro: José Olympio, 1974.

CASTOLDI, R.; POLINARSKI, C. A. A utilização de recursos didático-pedagógicos na motivação da aprendizagem. In: SIMPÓSIO NACIONAL DE ENSINO DE CIÊNCIA E TECNOLOGIA.Anais... Ponta Grossa, 2009.

CLEOPHAS, M. G.; SOARES, M. H. F. B (org.). Didatização lúdica no ensino de Química/Ciências. São Paulo: Livraria da Física, 2018.

COSCRATO, G.; PINA, J. C.; MELLO, D. F. Utilização de atividades lúdicas na educação em saúde: uma revisão integrativa da literatura. Acta Paulista de Enfermagem, v. 23, n. 2, p. 257-63, 2010.

DIAS, B. C.; BOMFIM, A. M. A “Teoria do fazer” em educação ambiental crítica: uma reflexão construída em contraposição à educação ambiental conservadora. In: VIII ENPEC. Anais... Campinas, 2011. p. 1-12.

DOHME, V. Atividades lúdicas na educação: o caminho de tijolos amarelos doprendizado. Petrópolis: Vozes, 2003.

FERNÁNDEZ-ARROYO, J.; RODRÍGUEZ-MARÍN, F. Los procesos de enseñanzaaprendizaje relacionados con el agua en el marco de las hipótesis de transición. Revista Eureka sobre Enseñanza y Divulgación de las Ciencias, v.14, n. 1, p. 227-243, 2017.

FERNÁNDEZ-OLIVERAS, A.; CORREA, V. M.; OLIVERAS, M. L. Estudio de una propuesta lúdica para la educación científica y matemática globalizada en infantil.

RevistaEureka sobre Enseñanza y Divulgación de las Ciencias, v.13, n. 2, p. 373-383, 2016.

FREIRE PINTO, L.; CLEOPHAS, M. G. Adaptação do Arco de Maguerez como metodologia problematizadora na promoção de uma educação voltada para a água. Revista Educação Ambiental em Ação, Ano XVI, n. 60, 2017.

GALERA, M.; REYES, J. Influencia de Concept Cartoons en la motivación y resultados académicos de los estudiantes. Revista Eureka sobre Enseñanza y Divulgación de las Ciencias, v. 12, n. 3, p. 419-440, 2015.

GARCEZ, E. S. C.; SOARES, M. H. F. B. Um estudo do estado da arte sobre a utilização do lúdico em ensino de Química. RBPEC, v. 17, n. 1, p. 183-214, 2017.

GUIMARÃES, M. Por uma educação ambiental crítica na sociedade atual. Revista Margens 
Interdisciplinar, v. 7, n. 9, p. 11-22, 2013.

HERRERA, M. P. M.; BARBOSA, R. H. El juego y sus posibilidades en la enseñanza de las ciencias naturales. Innovación Educativa, v. 14, n. 66, p. 41-63, 2014.

KINGSLEY, T. L.; GRABNER-HAGEN, M. M.Gamification: Questing to Integrate Content Knowledge, Literacy, and 21st-Century Learning.Journal of Adolescent \& Adult Literacy, v. 59, n. 1, p. 51-61, 2015.

MICHAEL J. Where's the evidence that active learning works? Advances in Physiology Education, v. 30, n. 4, p. 159-67, 2006.

NAFIATI, D. a. Dehumanization of teching and learning activities on social science subject. Dinamika Pendidikan, v.10, n.2, p. 125-133, 2015.

NIEL, M. Anestesiologistas e uso de drogas: um estudo qualitativo. $149 \mathrm{f}$. Dissertação (Mestrado em Ciências) - Escola Paulista de Medicina, Universidade Federal de São Paulo, São Paulo, 2006.

NILES, R. P. J.; SOCHA, K. Na importância das atividades lúdicas na educação infantil. Ágora: Revista de Divulgação Científica, v. 19, n. 1, p. 80-94, 2014.

OJA-PERSICHETO, A.J. Ludic prospects for science education in education home fundamental.Doxa, v. 19, n. 2, p.355-370, 2017.

PICCOLI, A. S.; KLIGERMAN, D. C.; COHEN, S. C.; ASSUMPÇÃO, R. F. A Educação Ambiental como estratégia de mobilização social para o enfrentamento da escassez de água. Ciência \& Saúde Coletiva, v. 21, n. 3, p. 797-808, 2016.

QUERIOZ, T. L. S. et al. Uma proposta interdisciplinar de educação ambiental a partir do tema água. Revista Brasileira de Extensão Universitária, v. 7, n. 1, p. 15-22, 2016.

RODRIGUES, M. L. Os desafios da política de educação no século XXI. Sociologia, Problemas e Práticas, v. 68, p. 171-176, 2012.

SÁNCHEZ-MARTÍN, J.; CAÑADA-CAÑADA, F.; DÁVILA-ACEDO, M. A. Just a game? Gamifying a general science class at university: Collaborative and competitive work implications: Collaborative and competitive work implications. Thinking Skills and Creativity, v. 26, p. 51-59, 2017.

SILVA, A. C. R.; LACERDA, P. L.; CLEOPHAS, M. G. Jogar e compreender a Química: ressignificando um jogo tradicional em didático. Revista de Educação em Ciências e Matemática, v. 13, n. 28, p.132-150, 2017.

TASSONE, V. C.; O’MAHONY, C.; MCKENNA, E. et al. (Re-)designing higher education curricula in times of systemic dysfunction: a responsible research and innovation perspective. Higher Education, p. 1-16, 2017. 
TOZONI-REIS, M. F. C. temas ambientais como "temas geradores": contribuições para uma metodologia educativa ambiental crítica, transformadora e emancipatória. Educação em

Revista, n. 27, p. 93-110, 2006.

TRIPP, D. Pesquisa-ação: uma introdução metodológica. Educação e Pesquisa, v. 31, n. 3, p. 443-466, 2005.

VÁZQUEZ-ALONSO, A.; MANASSERO-MAS, M. A. Juegos para enseñar la naturaleza del conocimiento científico y tecnológico. Educar, v. 53, n. 1, p. 149-170, 2017.

WINNICOTT, D. W. O brincar \& a realidade. Trad. J. O. A. Abreu e V. Nobre. Rio de Janeiro: Imago, 1975.

Recebido em: 7 de julho de 2018.

Aceito em: 6 de outubro de 2020. 